\title{
Short chain fatty acids dilate isolated human colonic resistance arteries
}

\author{
F V Mortensen, H Nielsen, M J Mulvany, I Hessov
}

\begin{abstract}
Colonic biopsy specimens were obtained from patients undergoing surgery for carcinoma of the rectum. Colonic resistance arteries (internal diameter 178-345 $\mu \mathrm{m}$ ) were dissected out under the microscope and mounted in a microvascular myograph capable of measuring isometric tension development. Experiments were designed to test compounds trophic to the gastrointestinal tract - namely, glutamine and the three short chain fatty acids, acetic, propionic, and butyric acid, for effects on vascular tone. Glutamine in concentrations up to $30 \mathrm{mM}$ neither constricted nor dilated the resistance arteries. The three short chain fatty acids alone and in combination, however, caused a concentration-dependent (range $0.1-$ $30 \mathrm{mM}$ ) dilatation of resistance arteries preconstricted with $50 \mathrm{mM} \mathrm{K}$, and this relaxant effect was unaffected by removal of the endothelium, presence of indomethacin, and preconstriction with vasopressin. These data suggest that the trophic effect of glutamine on intestinal mucosa cannot be explained through actions of this compound on the resistance vasculature. In contrast, the relaxant effect of short chain fatty acids on resistance arteries in vitro suggests that these compounds may be able to improve the colonic microcirculation in vivo, thereby providing an explanation for their trophic effect on intestinal mucosa.
\end{abstract}

Preservation of the anal sphincters is now possible with adequate extirpation of most rectal neoplasms. ${ }^{1}$ There is, however, a high incidence of leakage through the colorectal anastomoses. ${ }^{2-4}$ Radiological leakage has been reported to occur in $6 \%$ to $35 \%$ of anastomoses, ${ }^{25}$ and clinical leakage ranges from $2 \%$ to $18 \%$. $^{45}$

It has been suggested that microcirculatory failure is the main factor determining whether suture line leakage occurs. ${ }^{1}$ In 1969 Gruber $^{6}$ reported that canine experiments had shown that oxygen delivery to the tissues was maximal at a packed cell volume reading of $35 \%$ (equivalent in humans to a haemoglobin concentration of about $11 \mathrm{~g} / \mathrm{dl}$ ), decreasing sharply on either side of this figure. Likewise, in 1981 Tagart showed' that leaking of low anastomoses in male patients was associated with a mean haemoglobin concentration of $14.6 \mathrm{~g} / \mathrm{dl}$ while non-leakers had a mean concentration of $12.5 \mathrm{~g} / \mathrm{dl} \quad(\mathrm{p}<0.01)$. One explanation for these findings may be that a high haemoglobin concentration results in high blood viscosity and thereby decreased microcirculatory flow. Unfortunately, haemodilution - a way to obtain lower blood viscosity - is difficult to control. A better way to ensure increased microcirculatory flow to the resection edges of the anastomosis would be to use agents with a relaxant effect on the resistance arteries in the colonic wall.

Various gastrointestinal peptides, ${ }^{7}$ glutamine, ${ }^{8}$ and short chain fatty acids ${ }^{10}$ are trophic to the gastrointestinal tract. The aim of this study was to determine whether glutamine and the three short chain fatty acids, acetic, propionic, and butyric acid, have vasorelaxant effects on the resistance arteries in the human colonic wall and thus possible stimulatory effects on the microcirculation.

\section{Methods}

\section{SUBJECTS AND PREPARATIONS}

Six patients (aged 44-76 years, mean 54 years, three men) undergoing surgery for carcinoma of the rectum served as artery donors. Informed consent was obtained from all subjects, and the protocol of the study was approved by the local ethics committee. All the patients were normotensive (blood pressure not higher than 140/90 $\mathrm{mmHg}$ ), and none received any regular medication.

Immediately after resection of the affected rectal segment, a small piece of the bowel wall $(2 \times 3 \mathrm{~cm})$ was isolated and placed in cold physiological salt solution (see below). This piece of bowel wall was taken from an area as far away from the tumour as possible. Within 1 hour small arteries (a total of 12 arteries, normalised internal diameters $178-345 \mu \mathrm{m}$ ) were dissected from the bowel wall and mounted as ring segments (approximately $2 \mathrm{~mm}$ long) in a myograph capable of directly measuring their isometric wall tensions. "In four arteries the endothelium was removed mechanically with a $40 \mu \mathrm{m}$ steel wire. After equilibration for approximately 1 hour at $37^{\circ} \mathrm{C}$, the arteries were set to a normalised internal circumference $\mathrm{L}_{1}$, estimated to be 0.9 times the circumference they would maintain if relaxed and exposed to a transmural pressure of $13.3 \mathrm{kPa}^{12}$ At the start of each study the vessels were stimulated three times with K-physiological salt solution (see below, with $118 \mathrm{~mm} \mathrm{KCl}$ substituted for $\mathrm{NaCl}$ ). These stimulations served as standardised control responses, and all arteries in this study produced more than $13.3 \mathrm{kPa}$ effective active pressure (equal to pressure against which vessels would contract). ${ }^{12}$

\section{EXPERIMENTAL STUDY}

Eight arteries were preconstricted with $\mathrm{K} 50$ (physiological salt solution with $50 \mathrm{mM} \mathrm{KCl}$ substituted for $\mathrm{NaCl}$ on an equimolar basis), and 

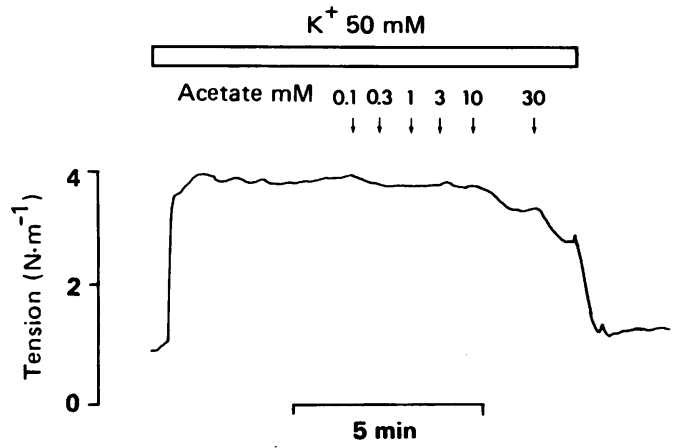

Figure 1: Vasodilation produced by acetate in a human colonic resistance artery (internal diameter $218 \mu \mathrm{m}$ ) preconstricted with $50 \mathrm{mM} \mathrm{KCl}$. Acetate was added cumulatively as indicated.

acetate, propionate, butyrate, and the three compounds in mixture according to the proportions of Sakata and Engelhardt ${ }^{13}$ were tested for possible relaxant effects. Relaxation curves were obtained by increasing the concentration of drugs cumulatively by a factor of $3 \cdot 2$ (half $\log$ increments)

In four arteries preconstriction was achieved with vasopressin $(5 \mathrm{mU} / \mathrm{ml})$, the endothelium was removed, and indomethacin $(14 \mu \mathrm{M})$ was present throughout the experiment. Absence of an acetylcholine-mediated $(1 \mu \mathrm{M})$ relaxation was interpreted as successful removal of the endothelium. ${ }^{14}$

Four arteries were preconstricted with K50 and tested for possible relaxant effects of glutamine and also for possible constrictive effects of the compound.

\section{STATISTICS}

Values are expressed as mean (SEM). A two tailed, paired Student's $t$ test was used for testing changes in vascular tone for significance.

\section{DRUGS AND SOLUTIONS}

The composition of physiological salt solution was (mM): $\mathrm{NaCl} 119, \mathrm{KCl} 4 \cdot 7, \mathrm{CaCl}_{2} \cdot 2 \mathrm{H}_{2} \mathrm{O} 2 \cdot 5$, $\mathrm{MgSO}_{4} \cdot 7 \mathrm{H}_{2} \mathrm{O} 1 \cdot 17, \mathrm{NaHCO}_{3} 25, \mathrm{KH}_{2} \mathrm{PO}_{4} 1 \cdot 18$, $\mathrm{Na}_{2}$ EDTA $0 \cdot 026$, glucose $5 \cdot 5$. The solution was bubbled with $95 \% \mathrm{O}_{2}$ and $5 \% \mathrm{CO}_{2}$ to give a pH of 7.4. Stock solutions were prepared daily in

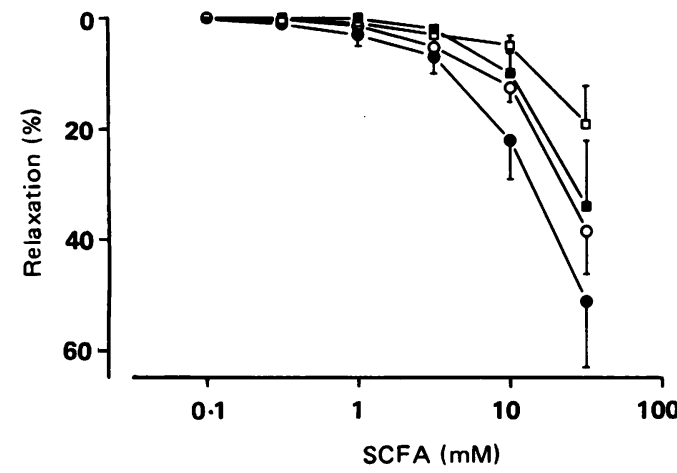

Figure 2: Effects of short chain fatty acids (SCFA) on human colonic resistance arteries already contracted with $50 \mathrm{mM}$ $\mathrm{KCl}:(\mathrm{O})$ acetate; $(\square)$ propionate; $(\square)$ butyrate. The solid circles (O) show the concentration of acetate in mixture with propionate and butyrate ((acetate):(propionate):(butyrate)= $60: 35: 25)$. Note the logarithmic division of the abscissa. Values are mean (SEM) (eight arteries).

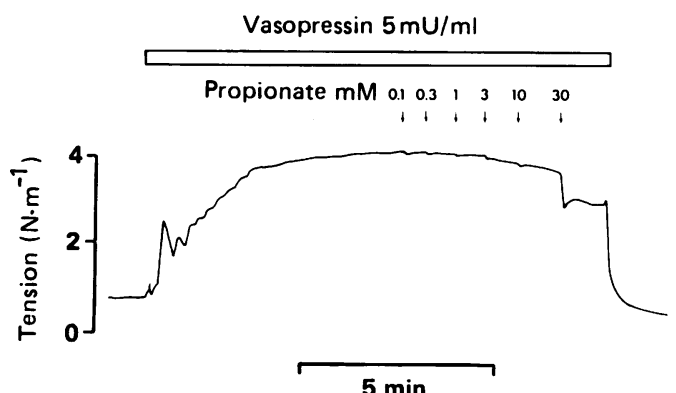

Figure 3: The effects of propionate in a $234 \mu \mathrm{m}$ colonic resistance artery precontracted with vasopressin $(5 \mathrm{mU} / \mathrm{ml})$. The endothelium had been removed mechanically and indomethacin $(14 \mu M)$ was present throughout. Propionate was added cumulatively as indicated.

distilled water. L-glutamine, sodium acetate trihydrate, sodium propionate, and sodium butyrate were purchased from Sigma Chemical Co, acetylcholine from Fluka AG, vasopressin from Sandoz, and indomethacin (Confortid) from Dumex (Denmark).

\section{Results}

The sodium salts of the short chain fatty acids dilated the colonic resistance arteries in a concentration-dependent manner after preconstriction with $\mathrm{K} 50$ (Figs 1 and 2). A mixture of acetate, propionate, and butyrate in the molar proportions 60:35:25 had a similar concentrationdependent relaxant effect (Fig 2). At $1 \mathrm{mM}$ the three short chain fatty acids in mixture caused a relaxation of $4(1) \%(\mathrm{p}<0.05)$. For acetate alone the relaxation at $3 \mathrm{mM}$ was $6(1) \%(\mathrm{p}<0.05)$. Removal of the endothelium, the presence of $3 \mu \mathrm{M}$ indomethacin, or preconstriction with $5 \mathrm{mU} / \mathrm{ml}$ vasopressin did not affect the relaxant properties of the short chain fatty acids qualitatively (Figs 3 and 4 ). At $3 \mathrm{mM}$ the relaxations caused by the short chain fatty acids in mixture and acetate alone were $4(1) \%$ and of $5(1) \%$, respectively ( $p<0.05$ in both cases). Addition of $60 \mathrm{mmol} / \mathrm{l}$ of the sodium salts of the three short chain fatty acids in the proportions noted above caused an increase of the $\mathrm{pH}$ in the physiological salt solution of $0.09(0.03)$ (three experiments).

Glutamine in concentrations up to $30 \mathrm{mmol} / \mathrm{l}$, however, had neither relaxant nor constrictor

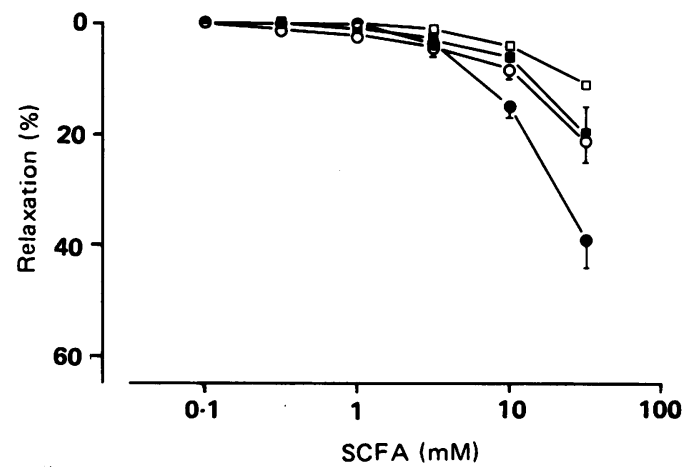

Figure 4: Effects of short chain fatty acids (SCFA) on human colonic resistance arteries already contracted with vasopressin

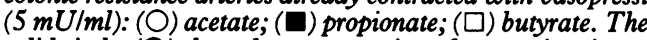
solid circles (O) show the concentration of acetate in mixture with propionate and butyrate ((acetate):(propionate): (butyrate) $=60: 35: 25$ ). Note the logarithmic division of the abscissa. All the vessels had the endothelium removed mechanically and indomethacin $(14 \mu M)$ was present throughout. Values are mean (SEM) (four arteries). 


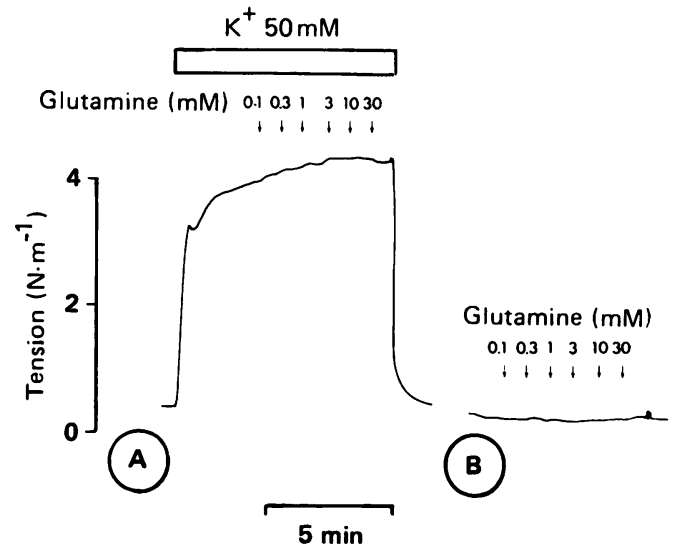

Figure 5: (A) Lack of effect on colonic resistance artery tone of adding glutamine to the vessel chamber. The right panel $(B)$ shows the lack of effects of glutamine on resting resistance arteries.

effects on the colonic resistance vessels (four vessels; Fig 5).

\section{Discussion}

For many years a nasogastric tube has been part of the traditional regimen after intestinal resections, thereby prohibiting early oral feeding. Consequently the colon is deprived of the dietary fibres which under normal circumstances would be broken down into short chain fatty acids by bacterial fermentation. Under these circumstances the only other source for bacterial fermentation in the colon, and thus production of short chain fatty acids, are glycoproteins of the small intestinal mucus. ${ }^{\text {is }}$ The three major short chain fatty acids, acetic, propionic, and butyric acid, are trophic to the intestine in vivo, ${ }^{916} 17$ and butyrate is the primary energy substrate for rat colonocytes. ${ }^{10}$ Recently it has been shown that the occurrence of spontaneous anastomotic dehiscence was appreciably lower in a group of rats receiving intracolonic infusion of short chain fatty acids compared to a control group. ${ }^{18}$ Even supplementation of short chain fatty acids to parenteral nutrition on an isocaloric basis has been shown to be protective against intestinal mucosal atrophy in rats $^{19}$ - a common problem associated with parenteral nutrition. No satisfactory explanation, however, has been given for the beneficial effects of short chain fatty acids after intravenous administration.

The present study shows that sodium salts of short chain fatty acids, both separately and in mixture, have relaxant effects on the colonic resistance vessels in vitro. The small rise in $\mathrm{pH}$ caused by the addition of the short chain fatty acids makes it unlikely that the vasorelaxant effects of the compounds were mediated through this increase. Mechanical removal of the endothelium or the addition of a prostaglandin synthetase inhibitor (indomethacin) did not affect the relaxing properties of the short chain fatty acids. These observations therefore indicate that the relaxant effects of short chain fatty acids are not mediated by endothelium derived relaxing factors or prostaglandin $s^{14}$; the short chain fatty acids apparently relax the vascular smooth muscle cells in an unspecific manner. In rats glutamine is also known to be trophic to the intestine and the colon after intravenous administration, ${ }^{820}$ but the experimental data from this study do not suggest that this effect is due to an improved microcirculation. The lack of effect of glutamine on vessel tone allows us to rule out that the relaxant effects of short chain fatty acids were due to a timedependent loss of contractility. Thus the concentrations of short chain fatty acids used have a clear relaxant effect on human colonic resistance arteries in vitro.

There are several reasons for believing that the concentrations of short chain fatty acids used in this study are reached under physiological circumstances in the environment of colonic resistance arteries. Firstly, the total concentration of short chain fatty acids in the healthy human colon ranges from $131 \mathrm{mmol} / \mathrm{kg}$ in the caecum to $80 \mathrm{mmol} / \mathrm{kg}$ in the descending colon, ${ }^{21}$ and the absorption of short chain fatty acids is concentration-dependent on both ionic and nonionic forms. ${ }^{22}$ Concentrations of short chain fatty acids in the millimolar ranges are therefore likely in the interstitial phase of the colonic wall. Secondly, short chain fatty acids are mainly produced in the colon, ${ }^{23}$ but only a minor fraction of the portal vein blood flow emanates from this organ. Nevertheless, concentrations of short chain fatty acids of $0.4 \mathrm{mmol} / \mathrm{l}$ have been reported in the human portal vein, ${ }^{21}$ and the concentration of short chain fatty acids must therefore be well above this level in the capillaries of the colonic wall, and, if anything, higher in the interstitial phase surrounding the arteries. Thus, the concentrations needed to produce dilatation (above $1 \mathrm{mM}$; Figs 2 and 4) are probably reached in the environment of the colonic resistance arteries in vivo.

From these findings one would expect a stimulatory effect of the short chain fatty acids on the microcirculation in the colonic wall, and this could, in part, explain the trophic effect of the short chain fatty acids in the colon. Such an action might also explain how short chain fatty acids, after intravenous administration in small doses, can be trophic to the intestine in rats. ${ }^{17}$

The relaxant effects of the short chain fatty acids seen in vitro allows us to speculate whether an improved microcirculation in vivo could be achieved by intracolonic or even intravenous infusion of short chain fatty acids. Adding short chain fatty acids to enteral or parenteral nutrition could be protective against both anastomotic failure and intestinal mucosal atrophy.

We are indebted to the vessel donors, the surgeons, and the theatre staff at Aarhus County Hospital for their cooperation in providing the human tissue. We thank Mr Børge Poulsen for help in preparing the illustrations.

1 Tagart REB. Colorectal anastomosis: factors reflecting success. F $R$ Soc Med 1981; 74: 111-8

2 Goligher JC, Lee PWG, Simpkins KC, Limbolt DJ. A controlled comparison of one- and two-layer technique of suture for high and low colorectal anastomoses. $B r \mathcal{F}$ Surgery 1977; 64: 609-14.

3 Goligher JC, Lee PWG, Macfie J, Simpkins KC, Lintott DJ. Experience with the Russian model 249 suture gun for anastomoses of the rectum. Surg Gynecol Obstet 1979; 148: $517-24$

4 Leicester RJ, Heald RJ. Towards fewer colostomies - the impact of circular stapling devices on the surgery of rectal impact of circular stapling devices on the
cancer. Br $\mathcal{F}$ Surgery $1980 ; 67: 198-200$.

5 Matheson NA, Irving AD. Single layer anastomoses after rectosigmoid resection. Brf Surgery 1975; 62: 239-42.

6 Gruber UF. Volume expansion and flow promotion in shock. Postgrad Med 7 1969; 45: 534-8. 
7 Goodlad RA, Wright NA. Peptides and epithelial growth regulation. Experientia 1987; 43: 780-4.

8 Grant JP, Snyder PJ. Use of L-glutamine in total parenteral nutrition. I Surg Res 1988; 44: 506-13.

9 Sakata T. Stimulatory effect of short chain fatty acids on epithelial cell proliferation in the rat intestine: a possible explanation for trophic effects of fermentable fibre, gut microbes and luminal trophic factors. Br $\mathcal{F}$ Nutr 1987; 58: 95-103.

10 Kripke SA, Fox AD, Berman JM, Settle RG, Rombeau JL. Stimulation of intestinal mucosal growth with intracolonic infusion of short chain fatty acids. Foumal of Parenteral and Enteral Nutrition 1989; 13: 109-16.

11 Mulvany MJ, Halpern W. Mechanical properties of vascular smooth muscle cells in situ. Nature 1976; 260: 617-9.

12 Mulvany MJ, Halpern W. Contractile properties of small arterial resistance vessels in spontaneously hypertensive and arterial resistance vessels in spontaneously hype

13 Sakata T, Engelhardt WV. Stimulatory effect of short chain fatty acids on the epithelial cell proliferation in rat large intestine. Comp Biochem Physiol 1983; 74A: 459-62.

14 Furchgott RF. Role of endothelium in responses of vascular smooth muscle. Circ Res 1983; 53: 557-73.

15 Zimmaro DM, Rolandelli RH, Koruda MJ, Settle RG, Stein PS, Rombeau JL. Isotonic tube feeding formula induces liquid stool in normal subjects: reversal by pectin. fournal of Parenteral and Enteral Nutrition 1989; 13: 117-23.
16 Sakata T, Yajima T. Influence of short chain fatty acids on the epithelial cell division of digestive tracts. $Q \mathcal{J}$ Exp Physio 1984; 69: 639-48.

17 Sakata T. Effects of indigestible dietary fibre bulk and short chain fatty acids on tissue weight and epithelial proliferation rate of the digestive tract in rats. F Nutr Sci Vitaminol 1986 32: 355-62.

18 Rolandelli HR, Koruda MJ, Settle G, Rombeau JL. Effects of intraluminal infusion of short chain fatty acids on the healin of colonic anastomosis in the rat. Surgery 1986; 100: 198205.

19 Koruda MJ, Rolandelli RH, Settle G, Zimmaro DM Rombeau JL. Effect of parenteral nutrition supplemented with short chain fatty acids on adaptation to massive small bowel resection. Gastroenterology 1988; 95: 715-20.

20 Wilmore DW Smith RJ, O'Dwier ST, Jacobs DO, Ziegle TR, Wang XD. The gut: a central organ after surgical stress. TR, Wang XD. The gut: a

21 Cummings JH, Pomare EW, Branch WJ, Nagler CPE Macfarlane GT. Short chain fatty acids in human large intestine, portal, hepatic and venous blood. Gut 1987; 28 : $1221-7$

22 Ruppin H, Bar-Meir S, Soergel KH, Wood CM, Schmitt J MG. Absorption of short chain fatty acids by the colon. Gastroenterology 1980; 78: 1500-7.

23 Cummings JH. Dietary fibre. Br Med Bull 1981; 37: 65-70. 